\title{
Interleukine-6 and TNF $\alpha$ blockers provide only partial and short-term temporal improvement in cryopyrin-associated periodic syndrome
}

\author{
Vladimir Dolgikh', Elena Kalashnikova², Ludmila Snegireva ${ }^{3}$, Lubov Rychkova', Anna Pogodina', Tatyana Knyazeva', \\ Mikhail M. Kostik ${ }^{3 *}$
}

From 21st European Pediatric Rheumatology (PReS) Congress

Belgrade, Serbia. 17-21 September 2014

\section{Introduction}

Cryopyrin-associated periodic syndrome (CAPS) is an inherited disease which is caused by gain-of function mutations in CIAS1 gene function resulting in increased secretion of active IL- $1 \beta$. IL- $1 \beta$ also can stimulate the production of other proinflammatory cytokines, such as IL-6, TNF $\alpha$ and so on (downstream cascade). The use of IL-1 blockers dramatically controls inflammation in CAPS patients and provide a persistent amelioration of the inflammatory manifestations. The data about using of IL- 6 or TNF $\alpha$ blockers in CAPS are very limited.

\section{Objectives}

The aim of our retrospective study was to describe the effects of IL- 6 and TNF $\alpha$ blockers in CINCA/NOMID syndrome.

\section{Methods}

We describe the effects of IL- 6 and TNF $\alpha$ blockers in 4 patients with CINCA/NOMID syndrome who were treated in their local hospitals by tocilizumab $(n=2)$, infliximab $(n=1)$ and adalimumab $(n=1)$. Patient\#1 (Pt1) with CINCA/NOMID was treated by TCZ due to lack of access to IL-1 blockers, Pt2 was misdiagnosed as systemic JIA and received TCZ, Pt3 was misdiagnosed as Crohn's disease and was treated by the infliximab and Pt4 was misdiagnosed as a TRAPS and was treated by adalimumab. All patients had concomitant corticosteroids (CS).

\footnotetext{
${ }^{3}$ Saint-Petersburg State Pediatric Medical University, Saint-Petersburg, Russian Federation

Full list of author information is available at the end of the article
}

\section{Results}

In Pt1 an initial clinical and laboratory response was observed after the first infusion (no fever, no rash). However 2 week after the first infusion the patients had a relapse of the disease. . The second infusion was less effective, leading to a partial clinical response with persistent elevation of acute phase reactants (CRP, ESR) and WBC. The third infusion was ineffective and associated with infusion reaction and TCZ was stopped.

In Pt2 TCZ was initiated after CS and methotrexate fall. During TCZ course fever and rash decreased but not disappeared, CRP, SAA and ESR were normalized but no changes in ear (senso-neural deafness), eye (conjunctivitis and uveitis) and brain damage (morning headaches with vomiting). Steroids were tapered but not discontinued due to flares of the disease.

In Pt3 two initial Infliximab infusions (every 2 weeks) were effective: no fever, no rash and normalized CRP and ESR. It was difficult to evaluate any changes in the organs damage due to small age of child. After $2^{\text {nd }}$ infliximab infusion Pt3 experienced the flare and $3{ }^{\text {rd }}$ infliximab infusion was ineffective and discontinued. Steroids were tapered but not discontinued due to flare of the disease.

In Pt4 adalimumab (40 mg sc every 2 weeks) was ineffective: only short-term decreasing of CRP and ESR. Girl still had all features of the disease and really controlled by only CS. She had impressive linear growth delay, open fontanels, hydrocephaly, chronic meningitis and acute phase reactants.

Later Pt2, 3, 4 were assessed by authors of this abstract and the CINCA/NOMID syndrome was diagnosed by clinically $(n=3)$ and genetically $(n=2,1$-negative mutations). Canakinumab was initiated in all children and provided prompt anti-inflammatory effect. 


\section{Conclusion}

The failure of anti-IL- 6 and anti-TNF $\alpha$ treatment in CAPS patients confirms the dominant role of IL- 1 in the pathogenesis of the disease and only IL-1 blockers strongly needed for these patients.

\section{Disclosure of interest}

None declared.

\section{Authors' details}

${ }^{1}$ Scientific Center of Family Health and Human Reproduction problems. Siberian Branch of the Russian Academy of Medical Sciences, Irkutsk, Russian Federation. ${ }^{2}$ Perm Regional Clinical Hospital, Perm, Russian Federation.

${ }^{3}$ Saint-Petersburg State Pediatric Medical University, Saint-Petersburg, Russian Federation.

Published: 17 September 2014

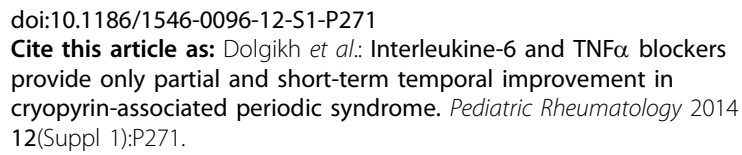

Submit your next manuscript to BioMed Central and take full advantage of:

- Convenient online submission

- Thorough peer review

- No space constraints or color figure charges

- Immediate publication on acceptance

- Inclusion in PubMed, CAS, Scopus and Google Scholar

- Research which is freely available for redistribution

Submit your manuscript at www.biomedcentral.com/submit 